\title{
Improvement of Theoretical Tennis Knowledge in Student Coaches at the Sports University of Greece
}

\author{
Alexandros Mavvidis ${ }^{1}$, Georgios Dallas' ${ }^{2}$, Argiris Theodosiou ${ }^{3}$, Ioannis Mavvidis ${ }^{4}$ \\ ${ }^{1}$ Department of Physical Education and Sport Science, Democritus University of Thrace, University Campus, Komotini, Greece \\ ${ }^{2}$ Department of Physical Education and Sport Science, National and Kapodistrian University of Athens, Athens, Greece \\ ${ }^{3}$ Department of Physical Education and Sport Sciences, Aristotle University of Thessaloniki, Thessaloniki, Greece \\ ${ }^{4}$ Department of Civil and Environmental Engineering, Imperial College London, London, UK \\ Email: *argtheodosiou@phed.auth.gr
}

How to cite this paper: Mavvidis, A., Dallas, G., Theodosiou, A. and Mavvidis, I. (2018) Improvement of Theoretical Tennis Knowledge in Student Coaches at the Sports University of Greece. Open Access Library Journal, 5: e4930.

https://doi.org/10.4236/oalib.1104930

Received: September 19, 2018

Accepted: October 20, 2018

Published: October 23, 2018

Copyright (c) 2018 by authors and Open Access Library Inc.

This work is licensed under the Creative Commons Attribution International License (CC BY 4.0).

http://creativecommons.org/licenses/by/4.0/

\begin{abstract}
Background: The primary aim of students specializing in a sport is to acquire full scientific knowledge on that sport. Furthermore, a qualitative objective of the specialization is to enable the future coaches to acquire good knowledge on the theoretical aspects of that sport. Methods: On the basis of the curriculum, the students of the Department of Physical Education and Sports (DPES) are examined on the theoretical knowledge they hold on issues related to tennis, e.g., technique, tactics, regulations, etc. at the beginning of the academic year, by answering a questionnaire of 80 questions. In order to assess the level of improvement of this knowledge the students answered the same 80 questions at the end of the academic year. The sample consisted of 23 male (11) and female (12) tennis students of the Department of Physical Education and Sport Science (aged $21.20 \pm 1.23$ years). Results: The results revealed significant improvement in all 5 knowledge groups between the two measurements. Although no significant differences were found between male and female students, this improvement was of a different kind. In the "technique" and "knowledge about the racket" related questions, males prevailed over females, whereas female students were superior in the "rules section". Conclusion: In the field of theoretical knowledge the level of education at the Department of Physical Education and Sport Science was, according to the findings of the study, satisfactory.
\end{abstract}

\section{Subject Areas}

Sports Science 


\section{Keywords}

Tennis, Theoretical Knowledge, Coaching Education

\section{Introduction}

Athletes' guidance on acquiring athletic skills, regardless of their age, requires general knowledge of the methodology of movements and exercises, pedagogy and other disciplines related to the learning process of sports movements. The students of the Department of Physical Education and Sport Science (DPESS) during their studies, based on the curriculum, specialize in a sport in order to acquire scientific knowledge that will enable them to become qualified coaches in that sport. Coaching is a very versatile process that requires coaches to continuously develop their knowledge and skills to keep up with their ever-changing environment with this improvement being influenced by other factors such as infrastructure, logistics, the environment and others [1] [2]. The coaching mentoring process includes "omologues" (such as psychology, biomechanics, exercise physiology, nutrition), sport specific knowledge (technical/tactical) and pedagogy (kinetic mental learning, coaching behavior) interacting to achieve the ultimate goal of coaching [3] [4] [5] [6] [7].

In order for someone to be an accredited coach, he/she should have knowledge of various fields of science such as physiology, sports technology, psychology, sociology and other fields that have been characterized as "evolutionary in status" [8]. The role of coaches is very crucial for the implementation of the training process. A coach's main goal is to improve the performance of his/her athlete and demonstrate awareness in a variety of situations while carrying out a big number of different tasks, but the main role is to develop and improve the performance of teams and individuals [9] [10]. The training and knowledge level of each coach is the most important asset for the qualitative guidance of their athletes [11].

One of the key elements of players' success is undoubtedly the quality of coaching that players receive [12]. To be a coach and work with excellence in different environments, one needs to master different skills and demonstrate expertise in different areas. According to the International Council for Coaching Excellence [13] the ability to work effectively in a complex and dynamic environment such as the sports coaching industry, requires a solid knowledge base (professional, interpersonal and intrapersonal) that supports various skills such as vision, organization, leadership, communication, building of personal relationships, evaluation, reflection, topped with or followed by a series of values that guide professional practice [13]. Recent literature [14] [15] presented a conceptual definition of the different knowledge that forms the basis of the practice of sports coaching. Although this definition subdivides the types of know- 
ledge, the authors reiterated that knowledge is interrelated, and by thinking of this in an isolated way could fail take into account the importance of the complex interactional nature of sports coaching. In this perspective [14] it is understood that the scientific and technical knowledge are the basic pillars that define the capabilities of a professional coach. There is limited knowledge on coaches' perceptions and access to sports science knowledge from other cultures. Moreover, it is unclear what effects years of coaching, gender, educational level, coaching certificate level, coaching team or individual sports, and being paid or unpaid have on coaches' perceptions and access to sports science knowledge. More recently, the ways coaches obtain new scientific knowledge has been a matter of debate [16]. Recent research indicated that the issue of transferring sport science knowledge to coaches has been difficult. Coaches are the intended beneficiaries of the outcomes of a large proportion of sport science research [17]. However, it has been perceived by coaches and researchers that a knowledge gap is present between them. In other words, there is incongruence between what sport research produces and coaches' knowledge needs. The learning process has effects in all kinds of human performance, such as cognitive and verbal, while in the physical performance, the visible result is an improved level of performance, which is not learning, but an indication that learning has taken place [18].

Specialized knowledge is often very important as well. For instance, biomechanical analysis of the motion is essential for the understanding of the technical execution of a specific technique in a particular sport [19]. Furthermore, motor learning, particularly early learning, involves attempts by learners to form an idea of the movement [20] or understand the basic pattern of coordination [18]. To achieve these goals, learners use cognitive [21] and verbal processes [22] to solve problems. The amount of information provided, how often and how long it will be given for, is known to affect the level of learning [23] [24].

There are two ways of receiving a tennis coaching diploma in Greece-through four full-time courses at the five University Departments of Physical Education and Sport Science (DPESS), along with a Physical Education teacher degree and through three-four week courses organized by the Governmental Secretariat of Sport (GSS) in conjunction with the National Tennis Federation. A study of Grivas and Mantis [25] supports that Greek tennis coaches personally estimate that they have a thorough knowledge $(M=5.2$ out of 7$)$ of tennis issues. Therefore, it is necessary to acquire a high level of theoretical knowledge on those skills, which are fundamental for the performing capability and high results in a sport [26] [27].

However, it is not well known whether the studying material provided during the course of study improves the existing level of theoretical knowledge. So, the purpose of this study was to determine the level of improvement in theoretical knowledge in the Department of Physical Education and Sport in the field of tennis, as well as the differences between men and women. It was hypothesized that both genders will possess the same amount of theoretical knowledge. 


\section{Methods}

\subsection{Participants}

Twenty-three Physical Education and Sport Sciences university students participated the study. Eleven were men $\left(n_{m}=11\right)$ and 12 women $\left(n_{w}=12\right)$. The mean age of the participants was $21.20 \pm 1.23$ years.

\subsection{Measures}

The students completed an 80 item questionnaire related to five fields of theoretical knowledge, which has been compiled with reference to international literature [5] [12] [19] [20] [26] [27] [28]. Out of these questions, 15 referred to technique (e.g. differences in technique between slice and top-spin groundstrokes), 12 to tactics (e.g. how the player moves to the net after a first serve), 33 to teaching-coaching (e.g. parameters for tennis performance), 14 to rules (e.g. how many lets one is allowed in tennis) and 6 to the tennis racket (e.g. what is the best tension for a racket). For every question four different choices were given and students were asked to identify the (unique) correct answer (multiple-choice).

\subsection{Procedures}

The questionnaire was completed with the presence of a member of the research team, with no bibliography or other assistance. After the completion of 2 semester courses the participants completed the same questionnaire to determine the level of learning.

\subsection{Analyses}

All analyses that were carried out using the statistical package SPSS v. 20. To test data's normality a Kolmogorov-Smirnoff test was made. Paired sample t-test was used to examine possible differences before and after the education program and independent $\mathrm{t}$-test was used to examine possible differences between groups ( $\mathrm{p}<$ $0.05)$.

\section{Results}

The responses from all participants are presented in Table 1. According to the results which are shown in Table 1, there was a better improvement in "rules" from $34.7 \%$ to $52.4 \%$ in "tactical" responses from $47.5 \%$ to $59.7 \%$ and in teaching-coaching from $53.13 \%$ to $63.78 \%$.

Even though no statistically significant differences were found between the two genders, small differences were observed. More specifically, as it is demonstrated in Table 2, in the improvement of knowledge in the "technical" men demonstrated better results than women, i.e. from $41.7 \%$ (men)/41.5\% (women) to $53.9 \%$ (men) $/ 45.2 \%$ (women), respectively, as well as in the knowledge of the "racket" from $65.1 \%$ (men)/53.53\% (women) to $74.2 \%$ (men)/68\% (women). 
Table 1. Differences in the theoretical knowledge before and after the education program.

\begin{tabular}{ccccc}
\hline & Pre & Post & & \\
\hline & $\boldsymbol{M} \pm \boldsymbol{S D}$ & $\boldsymbol{M} \pm \boldsymbol{S D}$ & $\boldsymbol{t}$ & $\boldsymbol{S i g}$ \\
\hline Technique & $41.67 \pm 11.58$ & $49.39 \pm 14.15$ & -2.099 & 0.054 \\
Tactics & $47.55 \pm 1.65$ & $59.74 \pm 12.48$ & -3.431 & 0.004 \\
Teaching-Coaching & $53.13 \pm 10.58$ & $63.78 \pm 10.49$ & -2.314 & 0.036 \\
Rules & $34.78 \pm 11.99$ & $52.46 \pm 15.62$ & -5.435 & 0.000 \\
Racket & $59.09 \pm 19.55$ & $70.98 \pm 19.60$ & -2.584 & 0.022 \\
\hline
\end{tabular}

Table 2. Differences in the theoretical knowledge between genders before and after the education program.

\begin{tabular}{cccccccccc}
\hline & \multicolumn{4}{c}{ Pre } & \multicolumn{4}{c}{ Post } \\
\hline & \multicolumn{2}{c}{ Male } & \multicolumn{2}{c}{ Female } & \multicolumn{2}{c}{ Male } & \multicolumn{2}{c}{ Female } \\
\hline & $\boldsymbol{M} D$ & $\boldsymbol{M}$ & $\boldsymbol{S} D$ & $\boldsymbol{M}$ & $\boldsymbol{S D}$ & $\boldsymbol{M}$ & $\boldsymbol{S} D$ \\
\hline Technique & 41.79 & 11.57 & 41.56 & 12.10 & 53.90 & 14.43 & 45.26 & 13.13 \\
Tactics & 47.68 & 11.24 & 47.44 & 10.59 & 61.32 & 12.53 & 58.30 & 12.81 \\
Teaching-Coaching & 53.07 & 10.31 & 53.18 & 11.26 & 64.00 & 10.90 & 63.57 & 10.59 \\
Rules & 38.01 & 11.73 & 31.82 & 11.93 & 50.62 & 11.27 & 54.16 & 19.14 \\
Racket & 65.12 & 24.10 & 53.57 & 12.91 & 74.21 & 20.22 & 68.02 & 19.40 \\
\hline
\end{tabular}

Women demonstrated better improvement over men in the "rules" from 38.0\% (men)/31.8\% (women) to $50.6 \%$ (men)/54.1\% (women).

\section{Discussion}

Improvement in theoretical knowledge is, as this study proved, substantial, as students had a generic learning on theoretical sports sciences for the last three years at the Sports University. This is particularly true for the subject of "Teaching-Coaching" where the general learning also covers the more specific one for the sport of tennis. The improvement in the average values is a good indication of the high-quality learning process for the specialization in tennis.

In other subjects clearly associated with tennis, such as the "Rules", the improvement was much more significant, a fact that is confirmed by the low mean value in the beginning and the respective value after the training/education $(34.78 \% / 52.46 \%)$.

In other subjects however, such as "Technique" and "Tactics", the improvement was considerably smaller, i.e. $41.67 \% / 49.39 \%$ in Technique and $47.55 \% / 59.75 \%$ in Tactics. This finding suggests that there is still space for further development regarding the level of progress on these subjects, which might indicate that the time period of the training is not sufficient to allow for further improvement, without at the same time excluding a possible need for a modified/improved training/education process that is likely to bring better results. 
Improvement in theoretical knowledge constitutes the basis for the further development of a professional coach. Male and female students are experiencing similar levels of improvement. This has practical application taking into consideration that the "theoretical knowledge" is the background and the main factor upon which the coaches will have to base their work [9] [16] [29].

In view of the rate of improvement by studying in a Sport University, it can be supported that the training of coaches should take place in such an institution, something that internationally does not happen today, for example, in Canada where $60 \%$ of coaches are in fact non-physical education teachers [30]. As discussed, in topics that are more fixed and specifically determined, such as "regulations", improvement is greater $(11.4 \% / 22.3 \%)$ among women, while in "technical" topics men show better improvement (4.3\%/12.3\%), probably because they appreciate and improve more in the act of the sports.

\section{Contributors}

All authors have read and approved the final manuscript.

\section{Conflicts of Interest}

The authors declare no conflicts of interest regarding the publication of this paper.

\section{References}

[1] Cushion, C.J., Armour, K.M. and Jones, R.L. (2003) Coach Education and Continuing Professional Development: Experience and Learning to Coach. Quest, 55, 215-230. https://doi.org/10.1080/00336297.2003.10491800

[2] Nash, C. and Collins, D. (2006) Tacit Knowledge in Expert Coaching: Science or Art? Quest, 58, 465-477. https://doi.org/10.1080/00336297.2006.10491894

[3] Groppel, J.L., Loehr, J.E., Melville, D.S. and Quinn, A.M., Eds. (1988) Science of Coaching Tennis. Leisure Press, Champaign, IL.

[4] Kriese, Ch. (1998) Coaching Tennis. McGraw-Hill Education, New York.

[5] Mavvidis, A. (2005) Backswing-Schwing das Ding, Tennissport-Fachzeitschrift für Tennistraining in Theorie und Praxis-Sindelfingen. Sportverlag Schmidt \& Dreisilker $\mathrm{GmbH}, 6$, 23-25.

[6] Abraham, A., Collins, D. and Martindale, R. (2006) The Coaching Schematic: Validation through Expert Coach Consensus. Journal of Sports Science, 24, 549-564. https://doi.org/10.1080/02640410500189173

[7] Funk, M.D. (2010) Kinematic Changes of the Tennis Forehand Ground Stroke as Post Contact Ball Speed Increases. Dissertation, Brigham Young University, Provo.

[8] Abraham, A. and Collins, D. (2011) Taking the Next Step. Ways Forward for Coaching Science. Quest, 63, 366-384. https://doi.org/10.1080/00336297.2011.10483687

[9] Jones, R.L., Armour, K.M. and Potrac, P. (2003) Constructing Expert Knowledge: A Case Study of a Top-Level Professional Soccer Coach. Sport, Education and Society, 8, 213-229. https://doi.org/10.1080/13573320309254

[10] Passmore, J. (2008) Psychometrics in Coaching: Using Psychometric Tools for De- 
velopment. Kogan Page Series, Michigan.

[11] Roetert, P. and Crespo, M. (2002) Myths of Tennis Coaching, ITF Tennis-Coaching, 26, 9-10.

[12] Duffy, P., Crespo, M. and Petrovic, L. (2010) The European Framework for the Recognition of Coaching Competence and Qualifications-Implications for the Sport of Athletics. New Studies in Athletics, 25, 27-41.

[13] International Council for Coaching Excellence-ICCE (2012) International Sport Coaching Framework. 1.1a Edition. Human Kinetics Pub., Champaign, Illinois.

[14] Côté, J. and Gilbert, W. (2009) An Integrative Definition of Coaching Effectiveness and Expertise. International Journal of Sports Science and Coaching, 4, 307-323. https://doi.org/10.1260/174795409789623892

[15] Gilbert, W. and Cơté, J. (2013) Defining Coaching Effectiveness: A Focus on Coaches' Knowledge. In: Potrac, P., Gilbert, W. and Denison, J., Eds., Routledge Handbook of Sports Coaching, Routledge, Abingdon, 147-159.

[16] Reade, I., Rodgers, W. and Spriggs, K. (2008) New Ideas for High Performance Coaches: A Case Study of Knowledge Transfer in Sport Science. International Journal of Sports Science and Coaching, 3, 335-354. https://doi.org/10.1260/174795408786238533

[17] Goldsmith, W. (2000) Bridging the Gap? Now There Is a Gap in the Bridge! ASCA Newsletter, 3, 24.

[18] Schmidt, R.A. (1991) Motor Learning and Performance: From Principles to Practice. Human Kinetics, Champaign.

[19] Elliott, B.C., Marsh, T. and Overheu, P. (1989) A Biomechanical Comparison of the Multi-Segment and Single Unit Topspin Forehand Drives in Tennis. International Journal of Sports Biomechanics, 5, 350-364. https://doi.org/10.1123/ijsb.5.3.350

[20] Gentile, A.M. (1972) A Working Model of Skill Acquisition with Application to Learning. Quest Monograph, 17, 3-23.

[21] Fitts, P.M. and Posner, M.I. (1967) Human Performance. Brooks/Cole, Belmont.

[22] Adams, J.A. (1971) A Closed-Loop Theory of Motor Learning. Journal of Motor Behavior, 3, 111-149. https://doi.org/10.1080/00222895.1971.10734898

[23] Swinnen, S.P., Schmidt, R.A., Nicholson, D.E., et al. (1990) Information Feedback for Skill Acquisition: Instantaneous Knowledge of Results Degrades Learning. Journal of Experimental Psychology: Learning, Memory, and Cognition, 16, 706-716. https://doi.org/10.1037/0278-7393.16.4.706

[24] Winstein, C.J. and Schmidt, R.A. (1990) Reduced Frequency of Knowledge of Results Enhances Motor Learning. Journal of Experimental Psychology: Learning, Memory, and Cognition, 16, 677-691. https://doi.org/10.1037/0278-7393.16.4.677

[25] Grivas, N. and Mantis, K. (2009) Coach Education: Models, Characteristics and Views of Greek Tennis Coaches. Science and Racket Sports, 4, 262-268.

[26] Bahamonde, R.E. and Knudson, D. (1998) Kinematic Analysis of the Open and Square Stance Tennis Forehand. Journal of Science and Medicine in Sport, 6, 88-101. https://doi.org/10.1016/S1440-2440(03)80012-9

[27] Ferrauti, A., Maier, P. and Weber, K. (2006) Tennis Training. Meyer \& Meyer Verlag, Aachen.

[28] Newell, K.M. (1985) Coordination, Control and Skill. In: Goodman, D., Wilberg, R.B. and Franks, I.M., Eds., Differing Perspectives in Motor Learning, Memory and Control, North-Holland, Amsterdam, 295-317. 
https://doi.org/10.1016/S0166-4115(08)62541-8

[29] Gillham, A., Doscher, M., Fitzgerald, C., et al. (2017) Strength and Conditioning Roundtable: Strength and Conditioning Coach Evaluation. International Journal of Sports Science \& Coaching, 12, 635-646. https://doi.org/10.1177/1747954117707484

[30] Camiré, M., Rocchi, M. and Kendellen, K. (2017) A Comparative Analysis of Physical Education and Non-Physical Education Teachers Who Coach High School Sport Teams. International Journal of Sports Science \& Coaching, 12, 557-564.

https://doi.org/10.1177/1747954117727629 